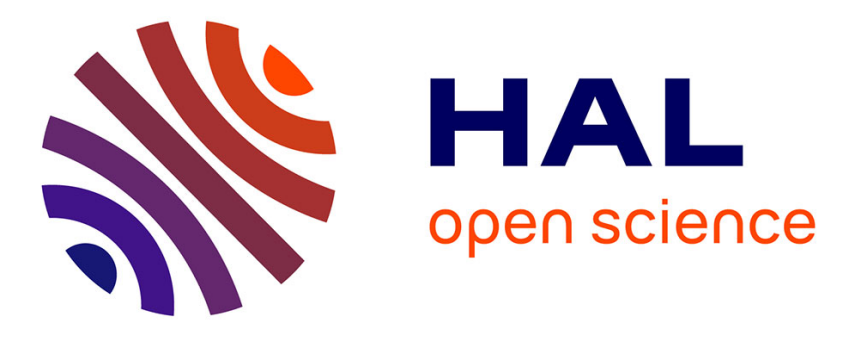

\title{
For a Sustainable Dialogue: The Green-Use (GU) Learning Cycles Concept
}

Livier Serna-Mansoux, Dominique Millet, Emilie Chapotot, Stéphanie Minel

\section{To cite this version:}

Livier Serna-Mansoux, Dominique Millet, Emilie Chapotot, Stéphanie Minel. For a Sustainable Dialogue: The Green-Use (GU) Learning Cycles Concept. ASME 2012 11th Biennial Conference on Engineering Systems Design and Analysis, Jul 2012, Nantes, France. pp.597-606, 10.1115/ESDA201282259 . hal-01723900

\section{HAL Id: hal-01723900 https://hal-univ-tln.archives-ouvertes.fr/hal-01723900}

Submitted on 18 Jan 2019

HAL is a multi-disciplinary open access archive for the deposit and dissemination of scientific research documents, whether they are published or not. The documents may come from teaching and research institutions in France or abroad, or from public or private research centers.
L'archive ouverte pluridisciplinaire HAL, est destinée au dépôt et à la diffusion de documents scientifiques de niveau recherche, publiés ou non, émanant des établissements d'enseignement et de recherche français ou étrangers, des laboratoires publics ou privés. 


\section{FOR A SUSTAINABLE DIALOGUE: THE GREEN-USE (GU) LEARNING CYCLES CONCEPT}

\author{
Livier Serna-Mansoux* \\ Laboratoire d'Ingénierie des Systèmes Mécaniques et des Matériaux \\ (LISMMA) \\ Supmeca Toulon \\ Toulon, Provence Côte d'Azur 83000 \\ Email: livier.serna@supmeca.fr
}

\author{
Dominique Millet \\ LISMMA \\ Supmeca Toulon \\ Toulon, Provence Côte d'Azur 83000 \\ France \\ Email: dominique.millet@supmeca.fr
}

\author{
Stéphanie Minel \\ ESTIA Recherche \\ ESTIA \\ Bidart, Pays Basque 64210 \\ France \\ Email: s.minel@estia.fr
}

\section{ABSTRACT}

Product design is now driven to the satisfaction of requirements all along the life cycle of the product, with an increased concern in environmental impact. A new concept, the Green-Use (GU) Learning Cycles, is proposed. It is used to determine the way a continuous, adaptive interaction between user and product can be established to improve environmental performance during use. It is structured by two levels of analysis (macro and micro) and a cyclic nature. These levels are the "Incremental user involvement levels", and the "Environmental Impact in Use". They are modelled around the notion of an evolution in cycles, from the initial state of the system product-user to a final stage which results in optimal use with minimal environmental impact. This work includes experimentation to support the new concept proposed, as well a method to use it.

\footnotetext{
*Address all correspondence to this author.
}

\section{INTRODUCTION}

Product design has lately been turning to the satisfaction of requirements all along the life cycle of the product, with an increased concern in environmental impact. Influenced by this, several proposals for product interaction favouring an environmentally friendly use (environmentally friendly use) have appeared. There is, nevertheless, a need for an approach that will address the changing circumstances associated with product use through time.

According to UNEP, the global materials' use increased eight-fold during the 20th Century. This means that presently, around 60 billion metric tonnes are calculated to be used per year. Since the Second World War, the use of renewable biomass has been replaced by the exploitation of mineral materials, and there's no evidence that this will slow down in the future. With increasing world population (it is calculated there will be 9 billion people in 2050), consumption per-capita of products and resources will only grow, with evident negative impact on the Earth's ecosystem. Sustainable consumption becomes then one 
of the global priorities [1].

On the other hand, Mont [2] states that the concern with consumption and product use in environmental terms is a relatively new approach. The consumption was viewed as part of the production phase and in consequence, as being a matter of technological improvements. Yet, although some technological innovations have indeed been made, the increasing scale of product consumption render them insufficient to address the environmental problems the world faces at present. The effort should include the way people consume and use products.

More specifically, consumption can be viewed like a twofold issue: one the one part, the product consumption as a an operation mainly concerned with how many units are bought and eventually disposed of in a given society. On the other hand, the use of the product, whereas more complex to analyse, influences its life-cycle as well as environmental issues such as household energy use levels (e.g., home appliances). Thus, by analysing the ways people use a product, new opportunities to modify the negative impact on the environment can be explored.

In this paper a new concept coined Green-Use (GU) Learning Cycles, is proposed. As it will be seen in the subsequent sections, there has been a surge of research in terms of the relationship between product use and environmental concerns such as pollution and energy expense. The scope of those studies have normally covered the interaction between user and product in a limited range of time and interaction style. In general, three areas of study were detected to present a pertinent opportunity for the Green-Use (GU) Learning Cycles concept to contribute.

The first is related with the timespan of interaction between user and product when the former is either learning or applying the acquired knowledge on how to exploit the functions of the latter in the most environmentally friendly way. The second addresses the approach of current research, which only concerns itself with one interaction, or several non-interdependent interactions. This, whereas easier to observe, is not a useful representation of reality, where several interactions occur at the same time between not only user and product, but context as well. Finally, the third is concerned with the limitation and delimitation of disciplinary approaches to the problem of environmentally friendly use. On one side of the scope, there are propositions driven by technology ignoring the behavioural realities of the product-user interaction. On the other, cognitive approaches that dismiss the possibilities of technology and product architecture and focus on "educating" the user to achieve environmentally friendly use.

These concerns are covered in the section "Interaction and environmentally friendly use of products". Experimentation have been carried out by the authors to support the pertinence of some of these concerns.

Then the GU Learning Cycles concept is presented and explained. In general terms, GU Learning Cycles concept proposes to determine the way a continuous, adaptive interaction between user and product can be established to improve envi- ronmental performance during use. It proposes two levels of analysis (macro and micro) and a cyclic nature. The first criterion is the "Incremental user involvement levels", which reflect the users interaction with the product according to environmental attributes. The second criterion, "Environmental Impact in Use", uses a referential "Theoretical Minimal Environmental Impact Factor" (TMENIF) calculated according to the product's architecture and technical functionality. There is an evolution in cycles, from the initial state of the system product-user to that in which GU Learning Cycles result in optimal use with minimal environmental impact. This work proposes a method for the GU Learning Cycles concept and exemplifies it with a theoretical case.

\section{INTERACTION AND ENVIRONMENTALLY FRIENDLY USE OF PRODUCTS}

In this section, three main aspects of product use oriented in terms of environmental concerns are presented. The aim is to understand how the GU Learning Cycles concept can contribute to the inclusion of sustainability into the use phase of a product. Experimentation has been done to complement the literature review.

\section{People forget}

Studies show that users tend to react positively to environmental awareness when first approached, but then return to old use habits (which can sometimes be environmentally counter productive). We developed an experiment in which the tendency to rebound to higher levels of consumption after having reacted to an environmental awareness campaign was shown. The experiment was based on the methodology proposed by Lilley in [3]. It considers 3 information modalities to build a link between user and product (Fig. 1), relating the power to make decisions. This power can either be focused on the human being direct action, or on the product function that "forces" the user to act in a certain way.

For our experiment we decided to consider the possibilities of behaviour influence with an existing product. The power of decision rests on the user's side (the upper part of Lilley's Fig. 1). We developed a mix where three types of "eco feedback" are used in two different chronological combinations: "persuasion by information", "persuasion by positive motivation", and "persuasion by guilt". The case study was the consumption of disposable towel paper from the dispenser in office toilettes. The 2 combinations were applied in two separate campaigns, each through a 3 month period.

The first campaign was developed with a group of 14 persons, 10 women and 4 men, between 25 and 59 years old. The "eco feedbacks" were communicated to the subjects in the following combination : 1) persuasion by information, 2) persua- 


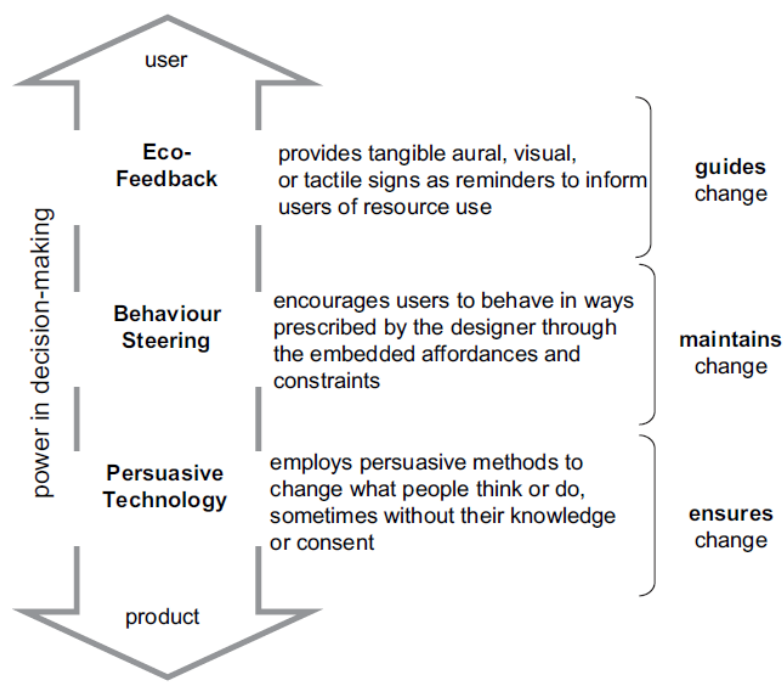

FIGURE 1. LILLEY'S STRATEGIES FOR DESIGNING SUSTAINABLE BEHAVIOUR [3].

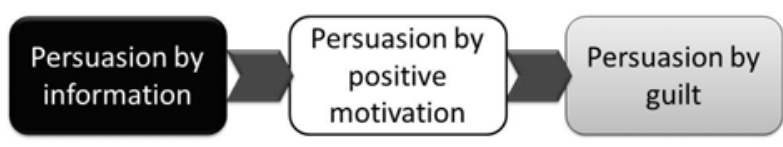

FIGURE 2. ORDER FOR CAMPAIGN 1.

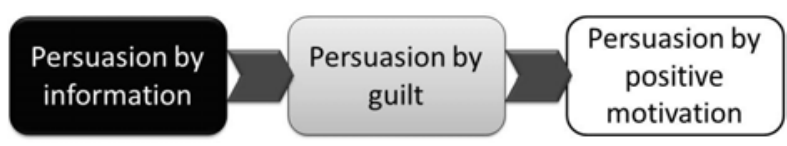

FIGURE 3. ORDER FOR CAMPAIGN 2.

sion by positive motivation, 3 ) persuasion by guilt. The second campaign was developed with a different group of people, in a different working space from campaign 1. It was comprised of group of 18 persons, 6 women and 12 men, between 25 and 51 years old. The "eco feedbacks" were communicated in the following order: 1) persuasion by information, 2) persuasion by guilt, 3 ) persuasion by positive motivation (Fig. 2 and Fig.3).

Both campaigns include measurements before, during, and after the different eco-feedbacks are communicated, and thus we can see the reaction and behaviour change in the subjects. In order to appreciate the overall impact of the campaigns, we recorded the measurement before, the lowest measurement during the campaigns, and the measurement after the campaigns. Out of the results we can observe that the tendency in most of the subjects is to return to higher consumptions after the campaign has finished (Fig. 4 and Fig.5). This implies the subjects either forget or loose interest in maintaining the changed behaviour (in this case, lower consumption of disposable towel paper).

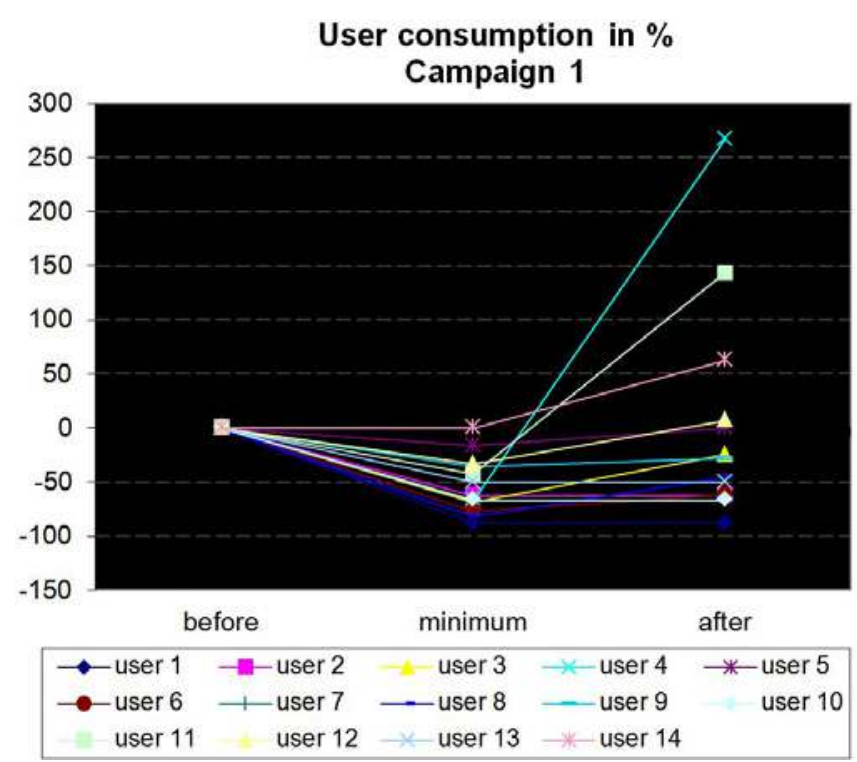

FIGURE 4. TENDENCIES IN CONSUMPTION FOR CAMPAIGN NO. 1.

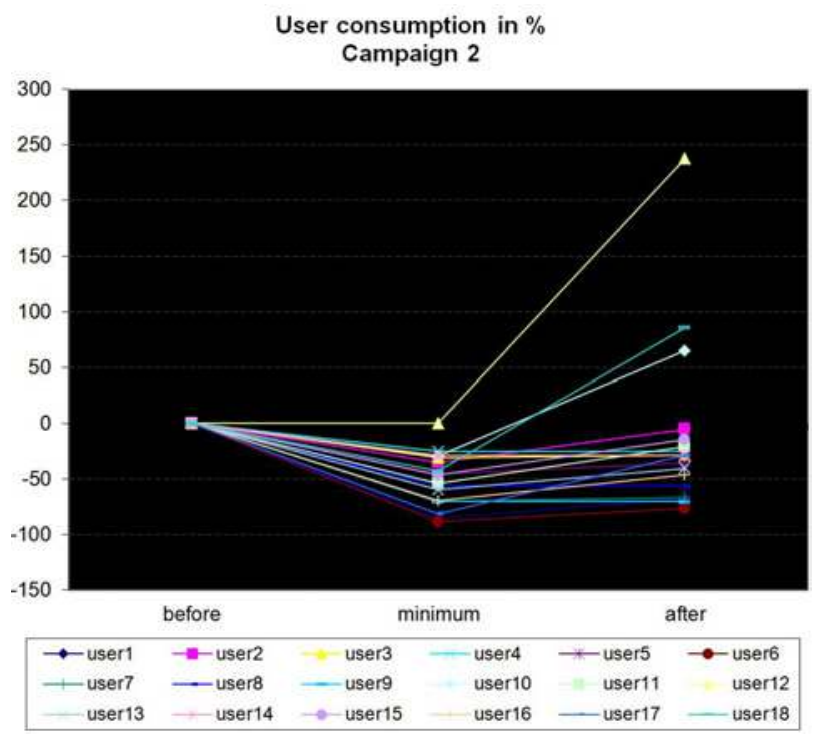

FIGURE 5. TENDENCIES IN CONSUMPTION FOR CAMPAIGN NO. 2.

\section{Simultaneous interactions does not equal the sum of them}

The environmentally-driven design of interactions, with the aim of reducing the energy consumption or extend the product's life for example, has commonly been approached as the inclusion of new interactions that would counteract non eco-friendly uses. Yet, it has been recognised that human behaviours can modify the intended function of a product by "misusing" it, this is, by 
changing the original intention of the product. This, according to Scott, can range from rejection, misuse or hacking [4] that counteracts use efficiency. Wever [5] offers a good review of what has been done in terms of modifying or even proposing new design approaches to consider human behaviour and interaction with the product when addressing environmental concerns. Out of all the approaches, the behaviour-centred approach, developed further in [4] is the most promising. It includes in the design problem the practices of the user, and in doing so, questions the existing interactions of products further than to answer to a human material need. Nevertheless, as in almost all of the design approaches being proposed in the sustainable design realm, the prospective part is left to an unbounded and rather unchecked process within the method. The possible deviation of product use due to human behaviour has not been considered explicitly to improve environmentally friendly use. The fact that people evolve and change their use-pattern can still offer insights on how to design products that would take advantage of this human behaviour evolution. Designed functions have always needed a close account of human reactions to them, and so the same should be done when addressing environmental concerns in use. Just as the average user will not really use the different power levels available in a typical vacuum cleaner (the average user will just switch to the highest level), the same user may not understand an environmentally oriented feature and end up not using it properly (or at all).

\section{Aggregation and eco-learning in product use}

As Lilley has pertinently proposed, the changes towards environmentally friendly use can go in two different directions: either towards the user's power to change or towards the product's functions that forces use in a certain way (Fig. 1). This, in new product solutions means the appropriate combination of both. In reality, though, external circumstances (external to the problem of environmentally friendly use) such as discipline segmentation and teamwork challenges, have mostly resulted in approaches that push mostly from the behavioural or from the technological part of the product. Sustainable solutions can be, for example, driven from the manufacturing or materials side of the product life cycle. Because it is an important factor to pollution and nature's degradation, the chemical composition of the product's materials was one of the first issues addressed by sustainable design. Several methods have been proposed. Yet, as shown in [6], [7], [8], [9], [10], [11], solutions pushed by the technical side of the product development address the manufacturing and/or materials problem, but also result in the product's architecture being modified. As a consequence of that, a modification in the user interactions arises. Nevertheless, since the userproduct interactions don't count for the initial approach, they are usually ignored in the results.

On the other hand, sustainable product research pushed from disciplines more connected to human behaviour and preferences hardly challenge the product's existing architecture in a direct way. They focus on human practices, habit modification and awareness. They have been useful in understanding consumer and user perceptions towards the product functions, and lately, the emergence of a "dematerialization" approach has been growing. Works like [12], [13], and [14] explore the paradigm change to a longer life for products and the reduction in mass production. This evidently points towards a modification in environmental concerns from a purely materialistic point of view, which can result in a modification of product architecture. This in turn, will mean a modification in product use and user behaviour towards it. Yet, a thorough study of the implications of technical modifications or aggregations of a product in the use phase has not been considered under these approaches as important as the material or technological study.

\section{THE GREEN-USE (GU) LEARNING CYCLES}

In order to respond to the need to address both human and technical issues related with environmentally friendly use, we have developed a concept called Green-Use (GU) Learning Cycles. It focuses the product development process in the nature of the interactions between user and product. These can be related to (Fig.6):

A) Functional needs: what the user wants the product to do in the first place, how the primary concern of the user is satisfied by the use of the product. This approach is somewhat larger than the purely functional approach classically addressed in product design. Usually, the way the product satisfies a need considers use at most from an ergonomic point of view. Nevertheless, extending the approach from an interaction point of view, the bio-mechanical relationship with the product (how it is gripped, operated, assembled, etc.) is only but a part of the analysis. The product is the materialization of the interaction between user and context to satisfy a need (e.g., how a user interacts with a coffee ingredients in order to satisfy its need for a coffee materializes in a coffee machine). This may seem only pertinent for new products, but the analysis on existing products and its context is useful too. Considering our aim is to implement the Green-Use (GU) Learning Cycles either on existing or on new products, it is important to explain the usefulness in product architectures already in the market. The insights given by a interactive approach to functional needs satisfaction can inform us where in the "use" phase the interaction between user and product can be improved without modifying the existing architecture, where can the product be partially modified (upgraded, as in [15]), or where the interaction can be exploited for our specific purpose of enhancing environmentally friendly use.

B) Contextual needs: these extend the relationships between user and product to the specific context where the product is positioned. Considering again the example of the coffee machine, the contextual needs address concerns such as the placement of 
the product (e.g. public place vs. private household), the number of different users it will have, how many times a day it will operate, where and when will it will be receive maintenance, and the such. In terms of our environmental concerns, this is essential to understand energy consumption and eventually, the repair, update, recycle or discard circumstances.

C) Evolutionary needs: these are poorly exploited if not completely ignored in the present product design approach. Product obsolescence and innovation as it has been traditionally understood consider the replacement of the product as the optimal situation. For this reason, it is only lately, triggered by the need to address global pollution and excess of energy consumption, that product development has turned to consider the possibility of the product being consciously designed to last more than it has up until now. As a result, the evolution of the user needs should be considered, both in terms of the functional and of the contextual needs. The main direction is always towards environmental awareness and best use of the product in terms or environmental impact.

These three types of interactions are the basis for the GU Learning Cycles approach. An analysis of the targeted product under their approach is considered the foundation of the concept. How the concept is constructed and structured, however, lies on a different levels of analysis (macro and micro) under which both the user and the product are observed. These levels are deployed through time, to be able both to understand and to influence the interaction cycles that happen between the product and the user. The levels of analysis (macro and micro), which will be explained in the following section, are:

a) The "Incremental user involvement levels", which reflect the user's progress in terms of interacting with the product according to environmental principles. This is a analysis that takes in account the phase of use in its long term cycle.

b) The "Environmental Impact in Use", uses a referential "Theoretical Minimal Environmental Impact Factor" (TMENIF) calculated according to the products architecture and technical functionality. It analyses the particular use on a particular moment.

In terms of the cyclic approach, it oscillates from descriptive to prescriptive(Fig.7). This means that in at times the information will be retrieved for the description of the situation as it is. At other moments of the development process, specially once the information for the descriptive phase has been recovered, the decision on what should be done (prescriptive) can be implemented. This oscillation, and the exact form and style the prescriptive phase will take, depend on three factors: 1)The complexity of the product: mainly related with technological concerns, some products will be limited in its prescriptive powers (persuasion by coercion) throughout the evolution of the use interaction product-user. Nevertheless, this can be shifted depending on the company's strategic planning. 2)The nature of the product's universe: there are products that follow a very fast track

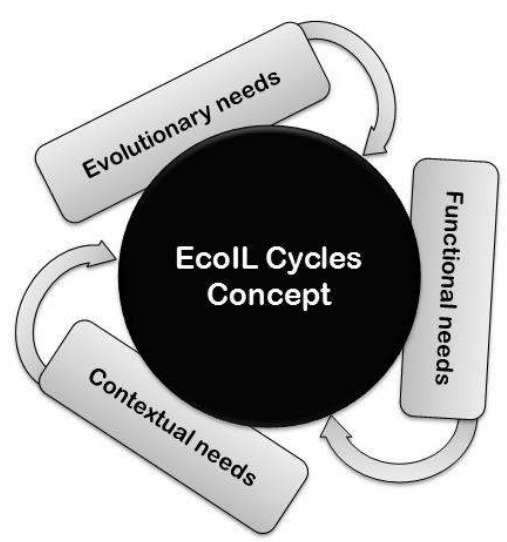

FIGURE 6. APPROACH FOUNDATIONS FOR THE GU LEARNING CYCLES CONCEPT

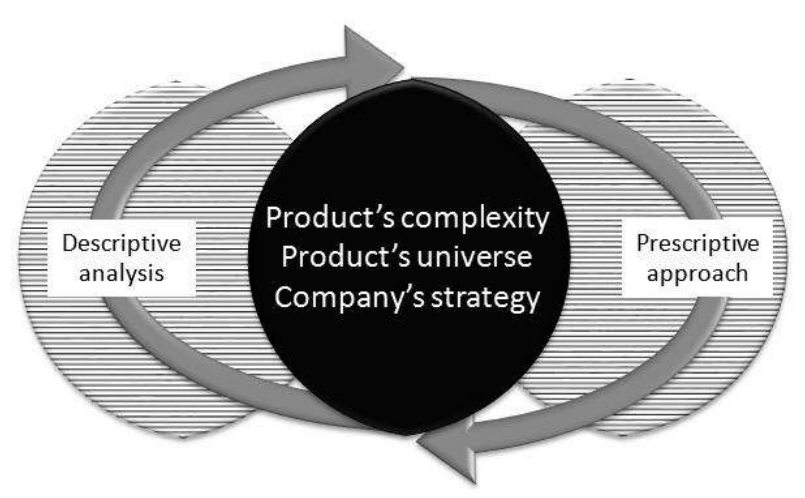

FIGURE 7. CYCLIC APPROACH FOR GU LEARNING CYCLES CONCEPT.

of functional change, and thus the cyclic approach has to take in account both technological and new uses paradigms shifts, and environmental awareness evolution. 3)The strategic vision of the company: the need to take in account the company's vision and mission as an actor in the market influences the nature of the cycles in that it can consider different types of products (e.g., a base product where the use evolves in terms of the service of the company, a product that evolves itself, a product that replaces parts of itself, a product that is completely replaces at a certain moment).

The GU Learning Cycles concept applies both to new product development and existing products with upgradable processes. In the section where the method is explained this will be further clarified. As an introduction, it is just important to notice that the integration of the GU Learning Cycles Concept in the ongoing improvement of existing products is coupled with the upgradable products vision developed by [16], [15]. This vision considers the rationalization of materials as an environmental long-term perspective. In this context, GU Learning Cycles concept can pertinently contribute by completing the product life 
cycle's analysis with the use phase.

\section{Incremental user involvement levels}

The "Incremental user involvement levels" are proposed in order to understand how the user's interaction with the product changes through time. The specific objective is to focus on the interaction related with environmental impact. Nevertheless, since the product and the user have a holistic interaction, the way the use evolves is not exclusively related to environmental concerns. We need then to have a general picture in order to focus on whatever part of the "use phase" may impact the environment.

Several approaches to understand user interactions with the product exist in the literature. These approaches come either from industrial ergonomics, studies to understand how a user learns to use a product, or how the user interacts with product messages. Some of these examples address the environmental factor, and we can find interesting insights in [17], [18], [19], [20].

Schmalz [17] considers the design for environmentally friendly use. In order to achieve it, a certain classification of interactions is proposed. In his research, he divides them into "functionality matching", "eco-feedback", "scripting", and "forced functionality". This is close to Lilley's interpretation of the decision power for change in use patterns [3]. The notion of evolution through time, though, is not explored.

Langdon [18] is concerned with product familiarity, and so he addresses the problem of time, even if in a rather limited scope. The proposal revolves around the loop "perceptioncognition-action". The individual develops perceptions of the product, then performs actions based on what he/she understands of this perception. Langdon takes the levels proposed by Rasmussen in 1986 [21] to understand user's processing of the actions taken. These can be: 1) "skill-based", where there's a rapid automated response, 2) "rule-based" where some conditional "ifthen" reasoning is present, and 3) "knowledge-based", where the reasoning is connected with symbolic notions extracted from mental models and induction.

The previous model is related in some ways to the three levels proposed by Norman [20]. He considers the first level to be "visceral", where the processing is deterministic, automatic, and subconscious, a result of our biological heritage. The second level is "behavioural". One key concept in this level is expectation. The expectation of the results of actions is somewhat related to the "rule-based" processing of Rasmussen. The third level Norman establishes is the "reflective" one, where self-awareness is located, and from where the analyses of the past and imagined futures are developed. This, again, is close to the "knowledgebased" level of Rasmussen, with its mental models and generalisations.

Neither Norman, nor Langdon or Rasmussen establish a chronological explicit sequence though. The one that evokes

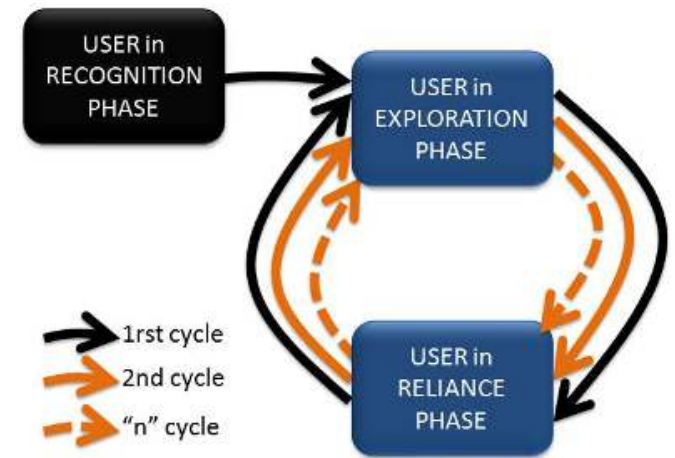

FIGURE 8. INCREMENTAL USER INVOLVEMENT LEVELS.

something of the like is Krippendorff ( [19] ch 3.6.7.). He establishes three phases of incremental involvement of the user and the product: recognition, exploration, and reliance. Each of these considers different kinds of user involvements, and different solutions in the product architecture to achieve them. Whereas recognition must be embedded in the product architecture in a very direct and explicit way, exploration and reliance are connected more with the interaction happening through time between the user and the product.

Another important insight is related to the factors that intervene in the "learnability" ( [19], ch 3.6.8.) of a product, which can be abstracted to three general principles: 1) diversity, the possibility to use the product in different ways and still make it work, 2) optimisation, giving the user the possibility to find short-cuts, and economizing effort, and 3) play, the possibility to have fun with the product.

In this work, we propose the "Incremental user involvement levels" definition, based on the observation of the user interaction with the product. The evolution proposed to be the reference are the three levels of "recognition", "exploration", and "reliance" the user passes through in learning to use the product. The way to measure the achievement of any of these phases is proposed to be done through the observation of the user when interacting with the product. The notion of automatic action is connected with the "recognition" phase, where as number of actions, dependence between actions and time involved in achieving the use of the product are the criteria related to the other two phases ("exploration" and "reliance"). The "indicator" serves to define the level where the user is according to Fig.8. The guidelines for each level are shown in Fig.9.

\section{Environmental Impact in Use}

The "Environmental Impact in Use" is connected to the results of the actions taken by the user on the product, and which result in a certain impact on the environment. The different impacts on the environment are classified by:

1) energy consumption: related to products that need an en- 


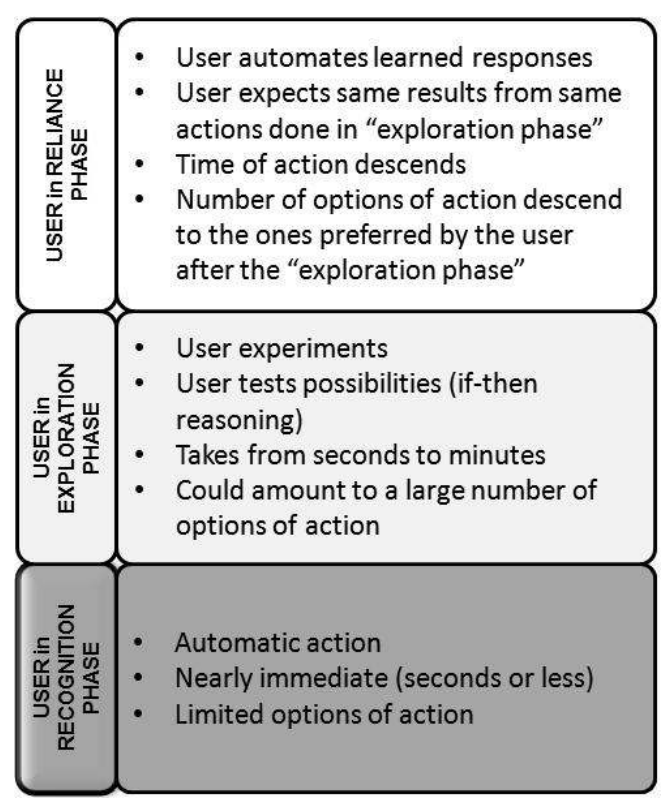

FIGURE 9. INCREMENTAL USER INVOLVEMENT LEVELS' GUIDELINES.

ergy source to function, such as electronic or fuel based products (telephones, computers, cars, coffee machines, etc.).

2) waste production: related to the by-products which are the result of the function, such as exhaust gases in cars, processed or discarded excess in machines, packaging associated with the product that's discarded once use begins.

3) material consumption (e.g., by replacement of parts as a result of degradation or misuse).

4) water consumption: for products that use water to work (e.g., showers, washing machines, faucets).

Depending on each of these, the minimal impact in use of the product is calculated. This is called "theoretical minimal environmental impact factor" (TMENIF) mainly because it doesn't consider the variability and uncertainty related with human interaction. It is taken as a reference to approach to, but not as an absolute and compulsory goal. The procedure to calculate the product's impact on the environment is adapted from the work of [22], as well as from the product specifications.

\section{THE GU LEARNING CYCLES CONCEPT'S METHOD}

The concept of GU Learning Cycles has been developed to be integrated either in the design process of new products, or the improvement process of existing products. Since the main objective is to drive the user towards an environmentally friendly interaction with the product, the concept works within a context of use, may this be already existing or in the making.

The method to apply the GU Learning Cycles concept unfolds as follows ((Fig.10):

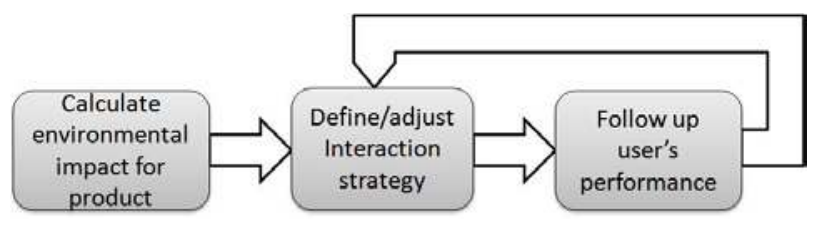

FIGURE 10. "GU LEARNING CYCLES" APPLICATION METHOD.

1) Calculate the environmental impact profile of the product.

2) Define the interaction strategy based on usability principles and the cyclic approach that derives from the use of the Incremental user involvement levels, so that the user will be put in the track of the "recognition-exploration-reliance" path.

3) Follow up the user's performance by recording and analysing data on the user-product interaction via the "Incremental user involvement levels" and the "Environmental Impact in Use".

4) Loop to step 2, always adjusting the strategy to improve performance or adapt to user's changes.

When using the GU Learning Cycles Concept in a product development process, the method falls within the loop between "concept search" and "conceptual design". It is once the problem has been understood, that the design team can integrate the need for the product to be environmentally friendly not only in use, but in general (Fig.11).

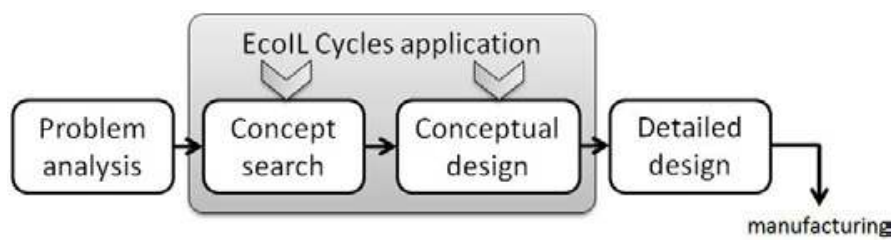

FIGURE 11. "GU LEARNING CYCLES" IN A NEW PRODUCT DESIGN PROCESS.

On the other hand, when applying the GU Learning Cycles Concept to an existing product, a different process approach is taken. Information about product and use, even productuser scenarios, is readily available. It is then approached as an "input-output" process, where the output is the improved product-service system (Fig.12).

\section{Product's environmental impact profile}

In terms of the first phase, the retrieval of the environmental impact profile of the product, we begin by locating the pertinence in the larger life cycle of the product. We consider as a reference for the environmental profile of the product the eight generic phases referred to by [23]: (1) material extraction and 


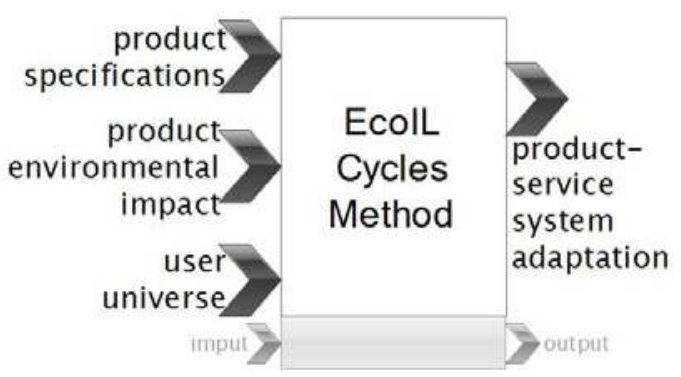

FIGURE 12. "GU LEARNING CYCLES" IN AN EXISTING PRODUCT SITUATION.

transformation, (2) component manufacturing and assembly, (3) component distribution, (4) product assembly, (5) product distribution, (6) product use, (7) product take-back, (8) component end-of-life. We then choose the sixth phase, product use, and concentrate on the analysis of it in order to understand the way the product may impact the environment when used.

Different methods to assess the impact exist, and in [24] there is a pertinent comparison between three of such methods: EDIP97 (Environmental Design of Industrial Products 1997), CML2001 (Life Cycle Assessment - An Operational Guide to the ISO Standards 2001), and Eco-Indicator 99. In the end, since the assessment used for the GU Learning Cycles concept limits itself to the use phase, we decide to follow the direction taken by [25]. They propose the Eco Indicator 99 due to the fact that it can render a single score. Their work includes the addition of four complementary indicators from the CML for objectivity and support purposes.

What we consider as the environmental profile of the product in the use phase is the performance explained previously in the section "Environmental Impact in Use". The TMENIF of the product is that performed with optimal product conditions and a simulation of use that would mean the minimal impact possible. This will most probably not be achieved during real use, or else not continuously, due both to human variability and product's degradation. Nevertheless, it will serve as a beacon to understand the real use and see if its impact evolves towards the TMENIF (which would be ideal) or away from it.

In order to illustrate what the GU Learning Cycles Concept can do, we consider the coffee machine example. The authors' research group is currently developing a long-term project revolving around the notion of upgradable/renewable products. This project accommodates the concept presented in this work by threading the upgrade/renew cycles of the product from a technical point of view, with the evolution of use we have talked about. In this case, the classifications used to explain the concept are "energy consumption" and "material consumption". The TMENIF for each impact is based on the ideal use, without errors or variability. This, as mentioned, will just serve as a guideline to know if real use is approaching it. In Fig.13 the graph as it would

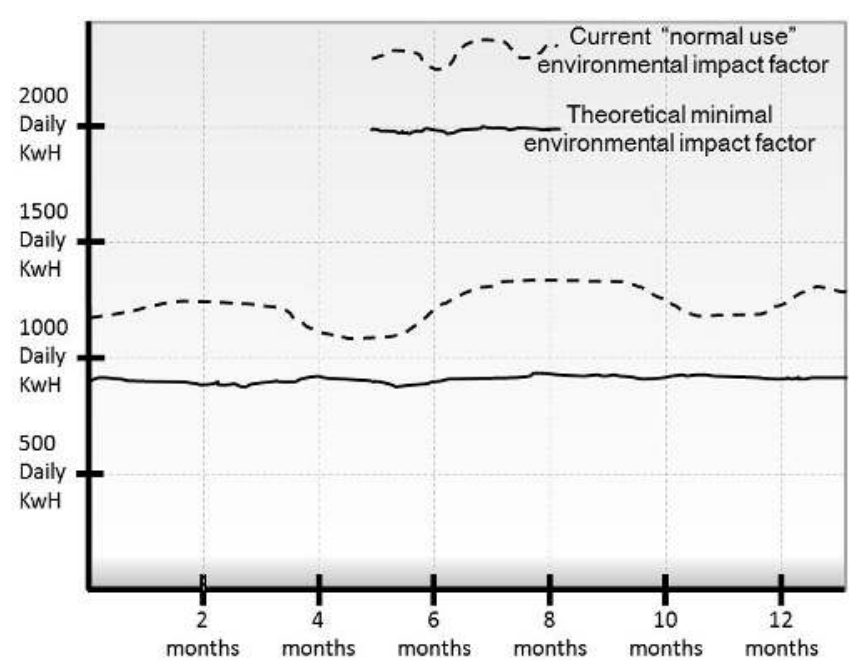

FIGURE 13. THEORETICAL MINIMAL IMPACT FACTOR VS. NORMAL USER IMPACT FACTOR.

be used is illustrated. The objective is to bring the "normal" use as close as possible to the TMENIF.

\section{Interaction strategy}

In phase two, the interaction strategy answers three questions: 1) What actions from the user conform a environmentally friendly use? 2) How do these actions relate to the learning process of the user "recognition-exploration-reliance"? 3) How will the product and the user interact to achieve environmentally friendly use? 4)How will the follow-up of the environmentally friendly use be done?

The interaction between product and user to answer to the first question should be simulated, whether the product is being designed or exists already. A use sequence must be visualized in order to understand how the product is to be designed or adapted to facilitate and optimal use (from the environmental point of view). Once the evolution path "recognitionexploration-reliance" explained previously is understood, it must be connected with the specific actions of the product analysed in order to understand where each action is taking place (the "recognition" level, or any of the others). The nature of the interaction can then be better specified, whether it will be embedded in the product architecture, with affordances or component semantics [19] or triggered through out the use of the product with feedback strategies.

Continuing with the coffee machine example, in Fig.14, the upgrade or renewal cycles are planned to take place periodically. Throughout each lapse of time, an example of the reinforcement of an environmentally correct use of the product is made by interacting with the user in different operations. The product can store the historical information of the user in order for the upgrade to 


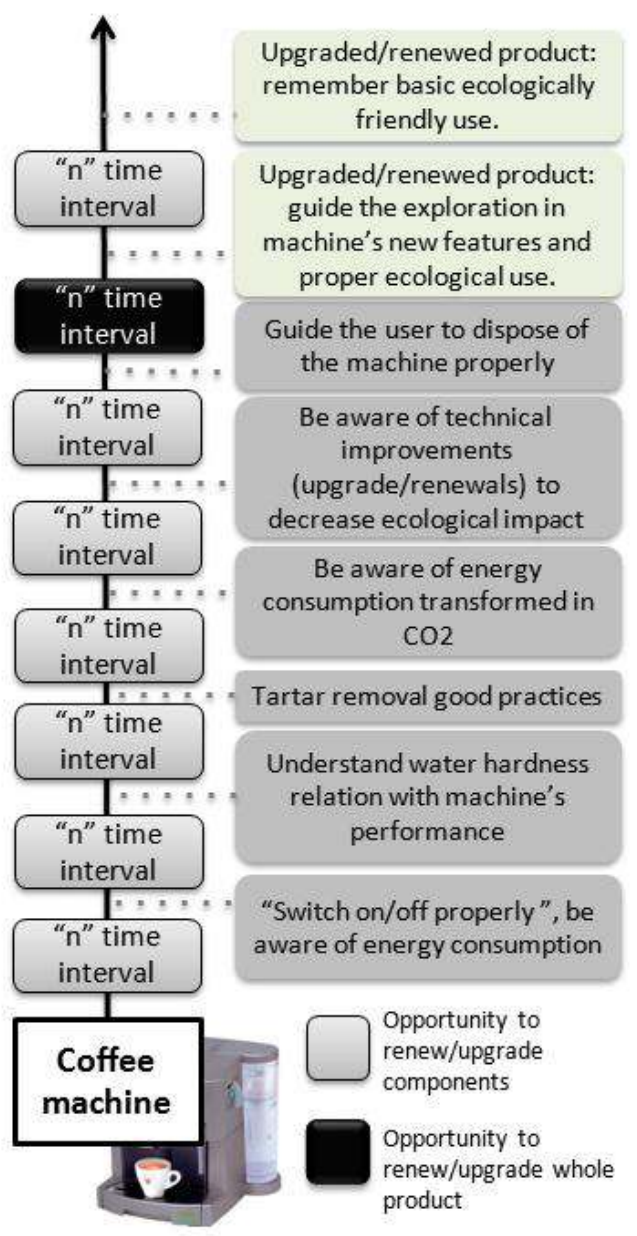

FIGURE 14. GU LEARNING CYCLES CONCEPT ILLUSTRATION: COFFEE MACHINE.

be not only technical but also in terms of the use of the product by the person. Along with the upgrade or renewal of the component or the whole product, information about historical use that has been stored can then be retrieved (thus calculating the "environmental impact in use"). Technical upgrades can then be customized to enable the best interaction possible between user and product to maintain or improve a low environmental impact.

\section{User's performance follow-up}

The performance of the user in terms of the interactions with the product are registered and analysed periodically in order to validate the strategy chosen before, or else to detect changes. This is why the concept has a cyclic nature. The loop is part of the method, as human behaviour rarely stays the same. The strategy can be adapted to be more persuasive or evolve according to the expertise acquired by the user. Continuing with the coffee machine example, and the strategy drafted in Fig.14, the

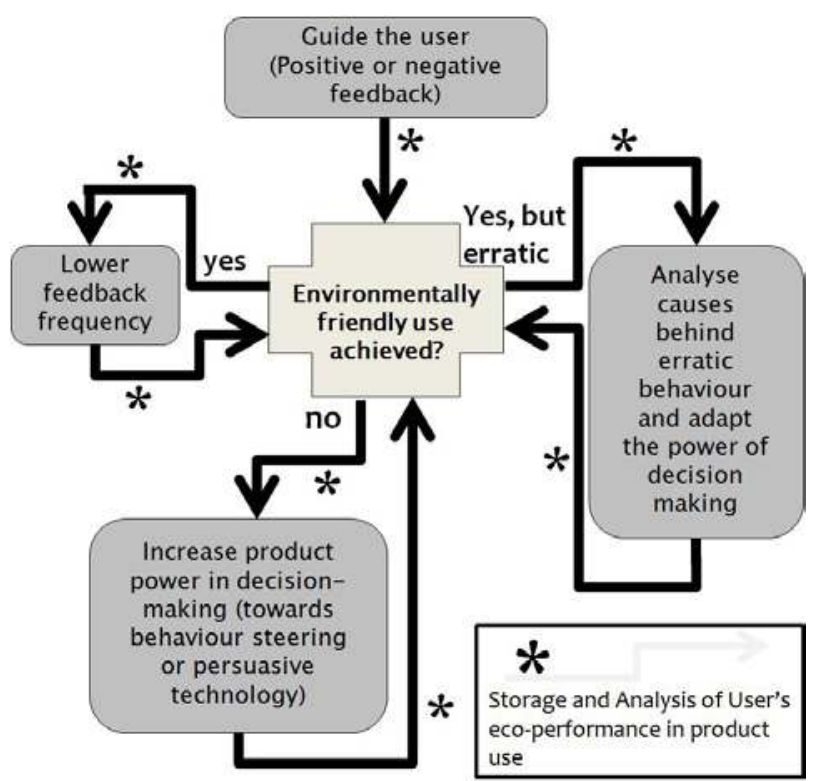

FIGURE 15. ILLUSTRATION OF STRATEGY ADAPTATION.

follow-up of the user's performance could show that the first target ("Switch on/off properly", be aware of energy consumption) hasn't been accomplished in the time interval theoretically considered in the beginning. The strategy of interaction can change in terms of persuasion style, until the registered data of energy consumption approaches the TMENIF. In Fig. 15 an illustration of the cyclic nature behind the follow-up is shown. The user's performance is terms of the environmental practice targeted is registered and the product adapts in terms of the success achieved. This illustration shows an interaction strategy based on information feedback, but it can be envisioned to include technical functionalities that would be activated in order to facilitate the environmentally friendly use or adapt it to a particular practice.

\section{Discussion}

The GU Learning Cycles Concept is an approach to product use that aims at achieving the lowest environmental impact possible in the use phase of a product. It proposes a cyclic, evolutionary interaction between user and product, where the latter adapts the communication needs of the former throughout the use phase of the product. It is the response to three general areas of opportunity in the environmentally driven design of products: the fact the user needs continuous follow-up in order to sustain continued environmentally friendly uses of the product; the problem of a one-time, generally initial interaction (commonly informative) that not always ensures prolonged eco-friendly use of the product; and the possibilities yet open to exploration in the realm of environmentally friendly use in product design. The GU Learning Cycles Concept considers the interaction of product and user 
from an environmental impact point of view. It proposes a several levels of analysis (macro and micro) as the guide to be able to know if the user is approaching environmentally friendly use or not. The Concept can be used in new product development processes, but one of its advantages is that it can be used to adapt and improve on existing products. The way to do so has been explained and illustrated. The different types of product interactions, whether they are embedded in the product as affordances or other semantic materialisations, or are an augmentation of the product (e.g., sensors) is one of the key areas to explore further. The nature of the evolution depending on the type of product, user needs and specific functionalities is also one aspect that will be refined as the Concept is tested. The contributions of it can help in the development of long-term use products, that an adapt to present context of technology and society.

\section{REFERENCES}

[1] UNEP, 2010. UNEP Year Book 2010: New Science and Developments in Our Changing Environment. UNEP/Earthprint.

[2] Mont, O., 2004. "Institutionalisation of sustainable consumption patterns based on shared use". Ecological Ergonomics, 50, August, pp. 135-153.

[3] Lilley, D., 2009. "Sustainable design education - considering design for behavioural change". Journal of the higher Education Academy, Engineering Subject Centre, 4(1).

[4] K. Scott, e. a., 2011. "Designing change by living change". Design Studies, in press.

[5] Wever, R., van Kuijk, J., and Boks, C., 2008. "User-centred design for sustainable behaviour". International Journal of Sustainable Engineering, 1(1), pp. 9-20.

[6] Stephen Poole, M. S., 1997. "Technological trends, product design and the environment". Design Studies, 18, pp. 237248.

[7] M. Hauschild, J. Jeswiet, L. A. Design for environment do we get the focus right? Annals of the CIRP. 53/1:1-4.

[8] Li-Hsing Shih, Yu-Si Chang, Y.-T. L., 2006. "Intelligent evaluation approach for electronic product recycling via case-based reasoning". Advanced Engineering Informatics, 20, pp. 137-145.

[9] Kobayashi, H., 2006. "A systematic approach to ecoinnovative product design based on life cycle planning". Advanced Engineering In, 20, pp. 113-125.

[10] Shana S. Smith, W.-H. C., 2011. "Rule-based recursive selective disassembly sequence planning for green design". Advanced Engineering Informatics, 25.

[11] E. Westkmper, L. Alting, G. A., 2001. "Life cycle management and assessment: Approaches and visions towards sustainable manufacturing". Proceedings of the Institution of Mechanical Engineers, Part B: Journal of Engineering Manufacture, 215(5), May, pp. 599-626.
[12] Heiskanen, E., and Jalas, M., 2003. "Can services lead to radical eco-efficiency improvements? - a review of the debate and evidence". Corporate Social - Responsibility and Environmental Management, 10(4), pp. 186-198.

[13] Dobers, P., and Wolff, R., 1999. "Eco-efficiency and dematerialization: Scenarios for new industrial logics in recycling industries, automobile and household appliances". Business Strategy and the Environment, 8(1), pp. 31-45.

[14] Cooper, T., 2004. "Inadequate life? evidence of consumer attitudes to product obsolescence". Journal of Consumer Policy, 27(4), pp. 421-449.

[15] Pialot, O., Millet, D., and Tchertchian, N., 2012. "How to explore scenarios of multiple upgrade cycles for sustainable product innovation: the upgrade cycle explorer tool". Journal of Cleaner Production, 22(1), pp. 19-31.

[16] Tchertchian, N., Millet, D., and Pialot, O., 2011. "Modular grouping exploration to design remanufacturable products". In Globalized Solutions for Sustainability in Manufacturing, J. Hesselbach and C. Herrmann, eds. Springer Berlin Heidelberg, pp. 413-418.

[17] Schmalz, J., and Boks, C., 2011. "Simultaneous application of design for sustainable behavior and linked benefit strategies in practice". In Proceedings of the 18th CIRP International Conference on Life Cycle Engineering, Springer, ed.

[18] Langdon, P., Lewis, T., and Clarkson, P., 2010. "Prior experience in the use of domestic product interfaces". Universal Access in the Information Society, 9(3), pp. 209-225.

[19] Krippendorff, K., 2006. The Semantic Turn. CRC - Taylor \& Francis.

[20] Norman, D., 2007. The design of future things. Basic Books.

[21] Rasmussen, J., 1986. Information Processing and HumanMachine Interaction. An Approach to Cognitive Engineering. North-Holland.

[22] Millet, D., Tchertchian, N., and Brissaud, D., 2009. "How to identify the most promising areas of environemental improvement at the early design stages of the design process?". International Journal of Design Engineering 2, 3, pp. 299-319.

[23] Gehin, A., Zwolinski, P., and Brissaud, D., 2009. "Integrated design of product lifecycles - the fridge case study". CIRP Journal of Manufacturing Science and Technology, 1, pp. 214-220.

[24] Dreyer, L., Niemann, A., and Hauschild, M., 2003. "Comparison of three different lcia methods: Edip97, cml2001 and eco-indicator 99". The International Journal of Life Cycle Assessment, 8, pp. 191-200. 10.1007/BF02978471.

[25] Tchertchian, N., and Millet, D., Accepted 2011. "Design for remanufacturing: What performances can be expected?". International Journal of Environmental Technology and Management, In print. 